TITLE:

\title{
Three Types of "Nauplius Y" (Maxillopoda : Facetotecta) from the North Pacific
}

$\operatorname{AUTHOR}(S)$ :

Ito, Tatsunori

\section{CITATION:}

Ito, Tatsunori. Three Types of "Nauplius Y" (Maxillopoda : Facetotecta) from the North Pacific. PUBLICATIONS OF THE SETO MARINE BIOLOGICAL LABORATORY 1986, 31(1-2): 63-73

ISSUE DATE:

1986-03-25

URL:

http://hdl.handle.net/2433/176117

RIGHT: 


\title{
Three Types of "Nauplius Y" (Maxillopoda: Facetotecta) from the North Pacific
}

\author{
By \\ Tatsunori Itô \\ Seto Marine Biological Laboratory, Kyoto University, Shirahama, \\ Wakayama 649-22, Japan
}

With Text-figures 1-4

\begin{abstract}
Three types of nauplius larvae of facetotectans are reported from the North Pacific off southern Honshu, Japan. Two of them resemble Hansen's type I and type IV and the other represents a previously unknown type, which is called type VII.
\end{abstract}

Although the occurrence of three types of facetotectan nauplius larvae (=nauplius y) (Crustacea: Maxillopoda) in the North Pacific was preliminarily reported by Itô (1984 b), description of the larvae has been postponed. I describe those larvae in this paper. They, however, do not necessarily represent all types of nauplius $y$ of the Pacific. In fact, I have recently found some nauplius larvae of a separate type together with a cypris y larva which is not yet recorded from the Pacific. I will describe them elsewhere.

In the following descriptions, shield-shaped exoskeleton which dorsally covers the forebody with three pairs of appendages is called "cephalic shield" (="anterior part of carapace" in the sense of Schram, 1970, 1972). Single process which forms the end of hind body is called "caudal horn."

The nauplius larvae reported in this paper were selected from some nauplii found in plankton samples collected in Tanabe Bay $\left(33^{\circ} 42^{\prime} \mathrm{N}, 135^{\circ} 21^{\prime} \mathrm{E}\right)$ off the Seto Marine Biological Laboratory on the Pacific coast of southern Honshu, the main island of Japan. The specimens were mounted onto slide glasses with glycerin and examined with the phase contrast microscope or differential interference microscope.

Before going further, I would like to express my sincere gratitude to Mr. S. Ohtsuka who placed his material at my disposal. Sincere thanks are also due to Dr. M.J. Grygier who indicated a Russian paper relevant to this study and provided me valuable information about his material. This study is supported in part by the Grant-in-Aid for Scientific Research, No. 58540482, from the Ministry of Education, Science and Culture, Japan.

\section{Nauplius Y, Pacific Type I}

(Fig. 1)

Material examined. A nauplius larva and an exuvium of a smaller nauplius (26-X-1983, Ohtsuka leg.).

Body (Fig. 1-A, B, G) $0.26 \mathrm{~mm}$ long, $0.165 \mathrm{~mm}$ wide, $0.09 \mathrm{~mm}$ thick (labrum

Publ. Seto Mar. Biol. Lab., 31 (1/2), 63-73, $1986 . \quad$ (Article 4) 

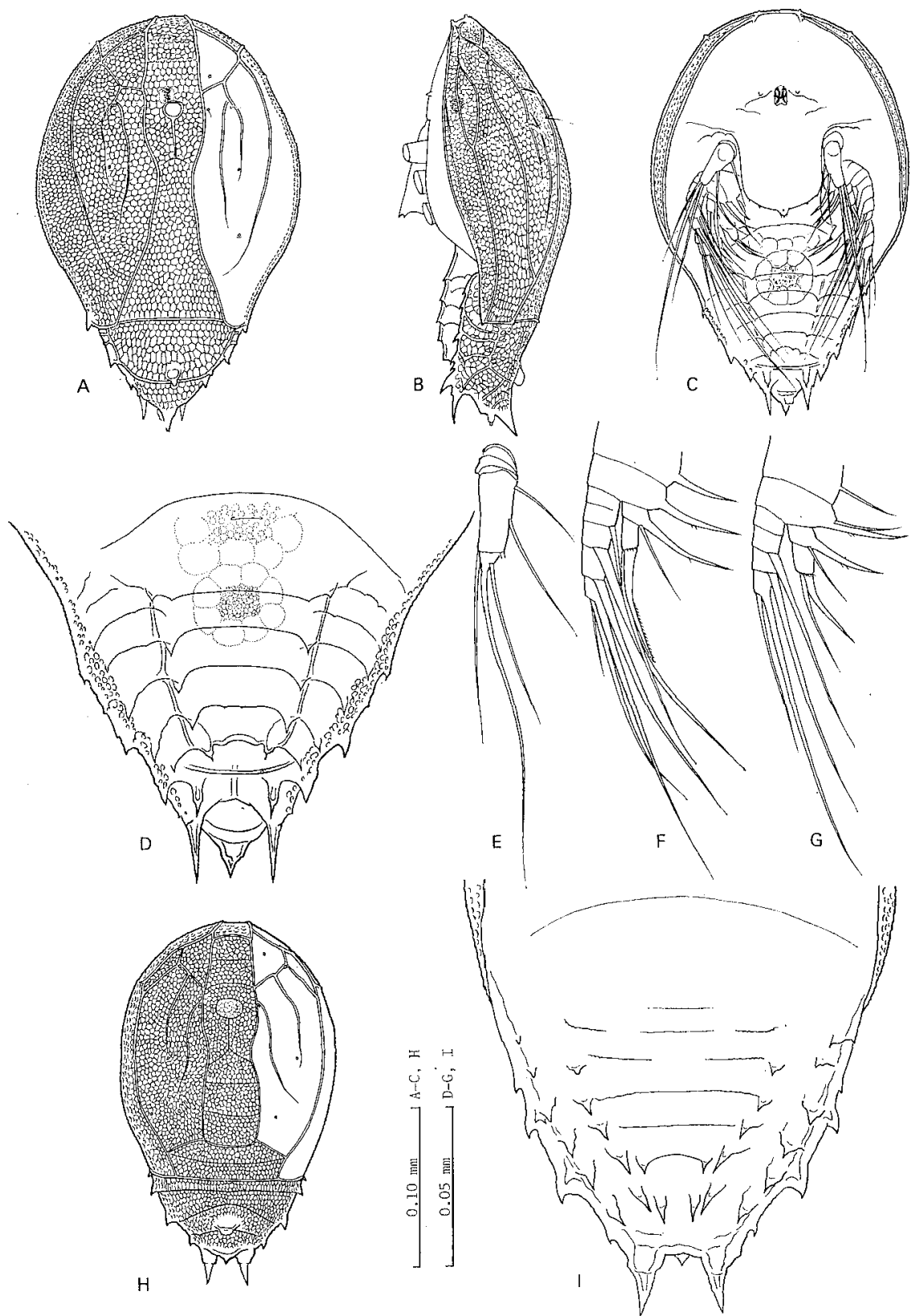

Fig. 1. Nauplius y, Pacific type I. A. Habitus, dorsal; B. Habitus, lateral; C. Habitus, ventral; D. Ventral view of hind body; E. First antenna; F. Second antenna; G. Mandible. H-I: Exuvium of a smaller nauplius. H. Habitus, dorsal; I. Ventral view of hind body. 
excluded), semitransparent and colorless though gut contents yellow-green. Nauplius eye red. Labrum (Fig. 1-C) well-developed, arising from a level a little anterior to the first antennae and extending to the base of the mandibles, forming a small projection apically. A pair of spiniform small protuberances arising from ventral surface near the nauplius eye.

Cephalic shield $0.19 \mathrm{~mm}$ long, sculptured with ridges on its surface made of mesh-like texture; a circular ridge placed above the nauplius eye and it embracing a smooth area (I call this structure "window"); posterior edge of the window extending posteriorly as a longitudinal ridge and ending in two faint branches; two long parallel ridges placed dorsally, which hold the window between them; each of the parallel ridges branching off outwards at a point a little anterior to the nauplius eye and at a frontal portion, and these two branches meeting with each other on a front-lateral portion and forming a polygonal plate; a bifurcate ridge extending from a midway of the posterior ridge of the polygonal plate described above, and a long ridge arising from a point near outer extremity of the posterior ridge of the polygonal plate; an encircled ridge forming a spindle-shaped plate at each front-lateral face (see Fig. 1-B), and a longitudinal ridge extending from the posterior end of this spindle-shaped plate and reaching a pointed posterior corner of cephalic shicld.

Hind body covered with a carapace-like exoskeleton, which is clearly demarcated from the cephalic shield by a suture and made of mesh-like texture, marginally sculptured with radial ridges which arise from a semicircular ridge; dorsocaudal organ (see Elofsson, 1971) represented by a swelling which is placed just anterior to the middle of the semicircular ridge; both lateral edges forming spiniform processes; ventral face with transverse ridges which form spiniform processes of different sizes (see Fig. 1-D); dorsal end provided with a short and thick caudal horn which is accompanied ventrally a blunt projection; a pair of sharp processes arising from ventral edge near the caudal horn.

First a ntenna (Fig. 1-E). Although I illustrate three segments for the first antenna, it is uncertain whether its first segment is a true segment. It might be a circular ridge, from which the appendage arises. Second segment short, with no seta. Third segment apically forming a small annulus which is delimited by a faint suture from the main part and bears two setae apically; the main part armed with two widely spaced setae on its inner face, a seta on outer distal face, and a short process on the distal extremity of its inner face. It is unlikely that the short process last mentioned is a broken seta, because an identical structure occurs on the other first antenna, too. S e cond a ntenna (Fig. 1-F). Coxa and basis alike, each armed with an endite which is represented by a spiniform process. Endopodite two-segmented; first segment short, inwards forming a long spiniform process accompanied with a fine seta; second segment cylindrical, armed with two apical setae, one of which is arched and spiniform. Exopodite four-segmented; first segment consisting of two incomplete annuli which are partially delimited from each other by a suture, armed with a small seta on its inner distal edge; second and third segments with a well-developed seta on each inner distal edge; fourth segment armed with 
three apical setae, one of which is very small. Ma n dible (Fig. 1-G). Coxa armed with a fine seta on its inner edge. Basis armed with an endite which is represented by a spiniform process accompanied with a fine seta. Endopodite as in the second antenna. Exopodite four-segmented; first segment with no seta; second and third segments armed with a seta on each inner distal edge; fourth segment armed with a seta on its inner distal edge and terminating in a fine seta.

Exuvium of a smaller nauplius: I suppose that this exuvium represents a younger stage of the nauplius described above. It was very transparent and its sculpture and mesh-like texture were easily seen. However, it was unfortunate that appendages were somewhat damaged. I give here a brief description on its body.

Body (Fig. 1-H) $0.21 \mathrm{~mm}$ long, $0.135 \mathrm{~mm}$ wide. Cephalic shield $0.155 \mathrm{~mm}$ wide; window filled with very faint mesh-like structures; parallel ridges which hold the window between them do not reach the posterior edge of the shield; each of the parallel ridges branching outwards a ridge at a point near the window; the posterior branch of the polygonal plate, which occurs at each outer side of the parallel ridges, not bifurcate. Hind body (Fig. 1-I) armed with spiniform projections ventrally; caudal horn rudimentary.

Remarks. Although these larvae from the Pacific resemble the type I larvae described by Hansen (1899) and Schram (1970) in the general appearance of the body and major sculpture on a frontal area of the cephalic shield, there are many discrepancies between them. Hence, I would like to call the above described larvae "nauplius y, Pacific type I."

According to Schram's paper which reported a series of type I larvae from Scandinavian waters in detail, his type I larvae have clear "plates" on the hind body. With respect to the shapes and distribution of the plates, the Pacific type I larvae do not accord with any of the larvae shown by him.

The caudal horn of Schram's larvae is clearly delimited at its base and is erected dorsally, whilst the counterpart of the Pacific larvae is not delimited basally and extends almost backwards.

The hind body of Schram's larvae bears a big dorsocaudal organ (="anus" in the sense of Schram, 1970). The dorsocaudal organ of the Pacific larvae is small as compared with the size of their hind body.

\section{Hansenocaris pacifica Itô}

(Fig. 2)

Material examined. A nauplius larva (26-X-1983, Ohtsuka leg.).

Body (Fig. 2-A, B) $0.41 \mathrm{~mm}$ long, $0.19 \mathrm{~mm}$ wide, $0.13 \mathrm{~mm}$ thick, colorless and semitransparent though a small portion of caudal region being yellowish. A red nauplius eye occurring a little anterior to labrum (Fig. 2-C; cf. Fig. 2-A and 2-B). Labrum (Fig. 2-G) short, placed between first antennae, membraneous, sculptured 


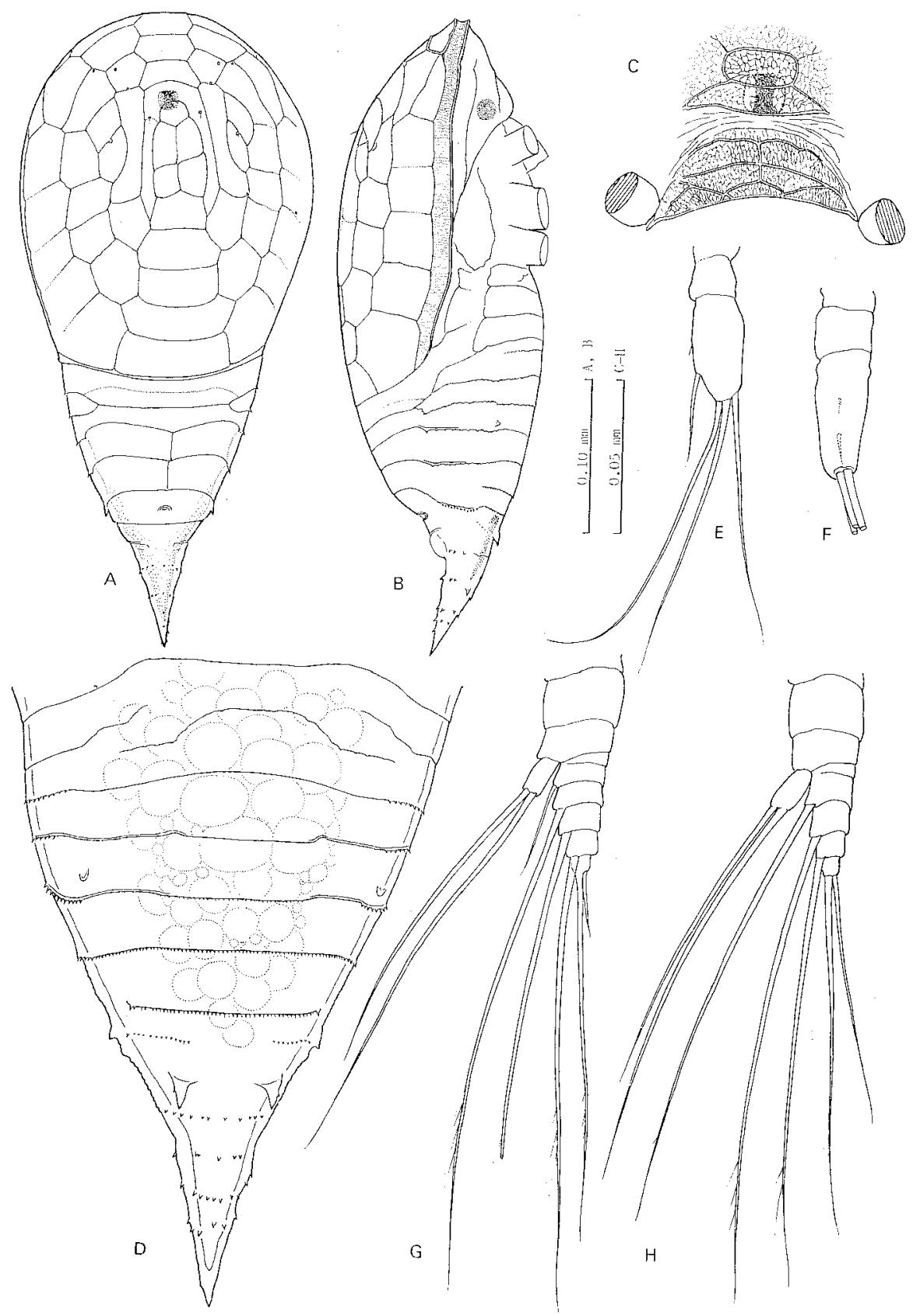

Fig. 2. A nauplius of Hansenocaris pacifica. A. Habitus, dorsal; B. Habitus, lateral; C. Ventral view of labrum and an adjacent area; D. Ventral view of hind body; E, F. First antennae; G. Second antenna; H. Mandible. 
with ridges as well as delicate mesh-like wrinkles. A circular ridge placed in front of the labrum, just below the nauplius eye.

Cephalic shield $0.25 \mathrm{~mm}$ long, with very delicate and mesh-like wrinkles (not illustrated, except for those of a marginal area : see Fig. 2-B) all over its surface except for the window, sculptured like a tortoise-shell pattern with ridges which form more than 50 (?52) "plates." Window above the nauplius eye $18 \mu \mathrm{m}$ wide, following two pairs of post-window plates and five, almost rectangular plates which increase their width toward posterior. Preceding to the window, a longitudinal row of four plates occurring: the plate immediate anterior to the window being contiguous (though separated by a faint ridge and/or a sensila) with two longitudinally stretched plates which hold the two pairs of post-window plates between them. Each of the longitudinally stretched plates accompanied with an elongate plate externally and a hexagonal plate posteriorly. The elongate plate accompanied externally with two small plates which are delimited from each other by a ridge with a sensila. Further externally two parallel rows of plates occur: the inner (dorsal) consisting of six almost hexagonal plates, the outer (ventral) consisting of six major plates, of which the anteriormost is subdivided into two plates by an almost horizontal suture.

Hind body devoid of carapace-like formation, tapering posteriorly, articulated superficially with ridges which are serrate or spinulose as illustrated (Fig. 2-A, B, D), terminating in a big caudal horn which bears a few circumambient rows of spinules and is accompanied with a pair of spiniform processes near its ventral base (see Fig. 2-D); a swelling (? dorsocaudal organ) which is not sclerotized and a pore occurring near the dorsal base of caudal horn (Fig. 2-B).

First a n t e n n a (Fig. 2-E, F) consisting of two clear segments plus an indistinct basal "segment" (? circular ridge); the terminal segment armed with three setae apically, a short seta on subapical inner face and a hairlike seta on the middle of its inner face. S e cond a n tenna (Fig. 2-G). Synpodite with very short precoxa, devoid of endite; coxa longer than basis. Endopodite represented by a small cylindrical segment which extends a little beyond first setiferous exopodite segment, armed with two long setae apically. Exopodite five-segmented; first segment consisting of two incomplete annuli which are partially delimited by an obscure suture, armed with a small seta on its inner distal edge; second, third, and fourth segments each with a long inner seta distally; fifth segment with a small seta and a long seta apically. M a n dible (Fig. 2-H). Synpodite and endopodite as in the second antenna. Exopodite four-segmented; first segment consisting of two incomplete annuli which are delimited partially by an obscure suture; first three segments each with a long inner seta distally; fourth segment armed with two long setae apically.

Remarks. It will be fully reported in a forthcoming paper that this nauplius represents an early larval stage of Hansenocaris pacifica Itô, 1985. As shown in Fig. 2, it is similar to the nauplius y type IV larvae which have repeatedly been reported from the Atlantic Ocean including its marginal seas (Hansen, 1899; McMurrich, 
1917; Bresciani, 1965; Schram, 1972) and the Adriatic Sea (Steuer, 1905), in the general pattern of distribution of "plates" on its cephalic shield. This nauplius especially resembles the larva 2 from Akeröya reported by Schram (1972, Fig. 3-A) in the arrangement of plates of the cephalic shield.

Despite of the close resemblance in the cephalic shield, the nauplius of $H$. pacifica is easily discernible from all of the Atlantic and Adriatic nauplii of the type IV so far reported because its hind body is much more elongate and tapers behind to form itself a big caudal horn. The hind body of the nauplius of $H$. pacifica does not differentiate a carapace-like structure, and occupies about $42.5 \%$ of its total body length, whilst the counterpart of Scandinavian nauplii of the type IV differentiates a carapace-like structure which is laterally well-defined, occupies only $33.3 \%$ even in the highest value (my estimation based on the Fig. 3A in Schram, 1972) and other previousely known nauplii of the type IV have smaller proportions for their hind body. In this connection, it would be noteworthy that the Scandinavian nauplii shown by Schram (1972) reduce the proportion of their hind body to the total body length as they grow.

The synpodites of the second antenna and mandible of the nauplius of $H$. pacifica are devoid of any endite, though previousely known larvae of the type IV have an endite on each coxa and basis of their second antennae and mandibles (see Schram, 1972, Fig. 5). This implies the nauplius of $H$. pacifica can develop without feeding.

\section{Nauplius Y, Type VII}

(Figs 3-4)

Material examined. A nauplius larva (26-X-1983, Ohtsuka leg.).

This nauplius contains a cyprid rudiment with a pair of compound eyes and pedigerous thoracic somites which are easily seen through the naupliar exoskeleton (see Fig. 3-A, B). I carefully examined the surface structures of cyprid carapace and abdomen to identify it but failed in my aim. I report this larva as nauplius $y$, type VII, since the type VI is preoccupied by Dr. M.J. Grygier for his larva of a previousely unknown type (pers. comm.).

Body (Fig. 3-A, B) pyliform in dorsal view, $0.38 \mathrm{~mm}$ long, $0.18 \mathrm{~mm}$ wide, 0.13 mm thick, colorless and semitransparent. Nauplius eye red. Labrum (Fig. 3-C) elongate and cxtending to the level of mandibles, widening posteriorly, sculptured with ridges and mesh-like wrinkles. Two small areas encircled with ridges occurring in front of the labrum.

Cephalic shield $0.25 \mathrm{~mm}$ long, with delicate wrinkles (not illustrated) all over its surface, sculptured with ridges which extend almost longitudinally but occasionally connect with each other; some small polygonal plates occurring on a frontal area above nauplius eye and along the mid-dorsal line; a simple "window" wanting.

Hind body almost conical, devoid of carapace-like structure, tapering posteriorly and ending in a thick caudal horn, sculptured with ridges which form a number of 
square plates dorsally, with serrate ridges and spinular rows ventrally; no dorsocaudal organ occurring in front of the caudal horn. Caudal horn (Fig. 3-D) about $42 \mu \mathrm{m}$ long, accompanied with a pair of spiniform projections at its ventral base, with some circumambient serrate ridges.

First a n te n $\mathrm{n}$ a (Fig. 4-A) consisting of two short basal segments and one long segment which bears a setula and a basally bifurcate seta apically. S e c o nd
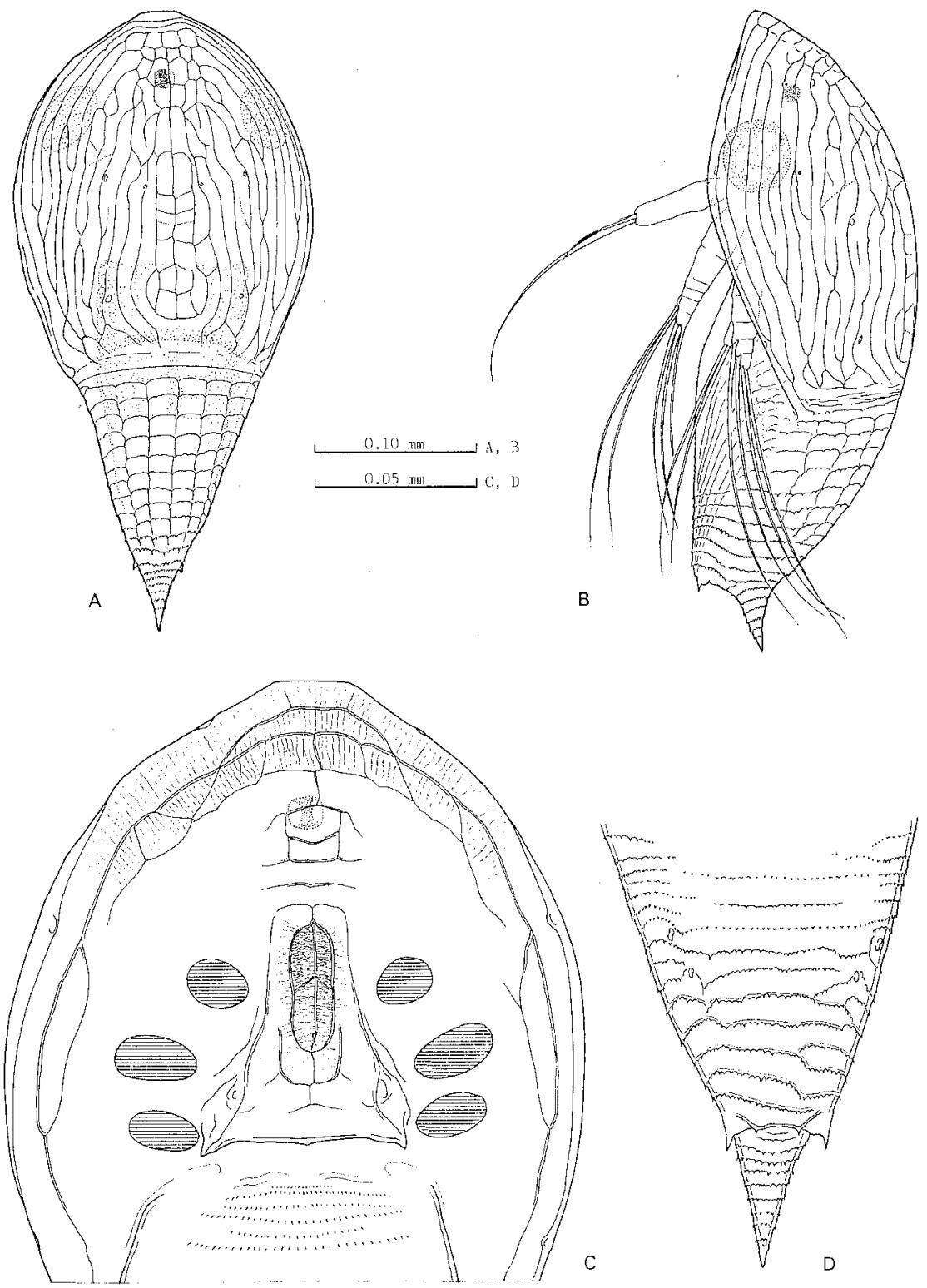

Fig. 3. Nauplius y, type VII. A. Habitus, dorsal; B. Habitus, lateral; C. Ventral view of forcbody (situations of three pairs of appendages are indicated by hatched areas); D. Ventral view of hind body. 


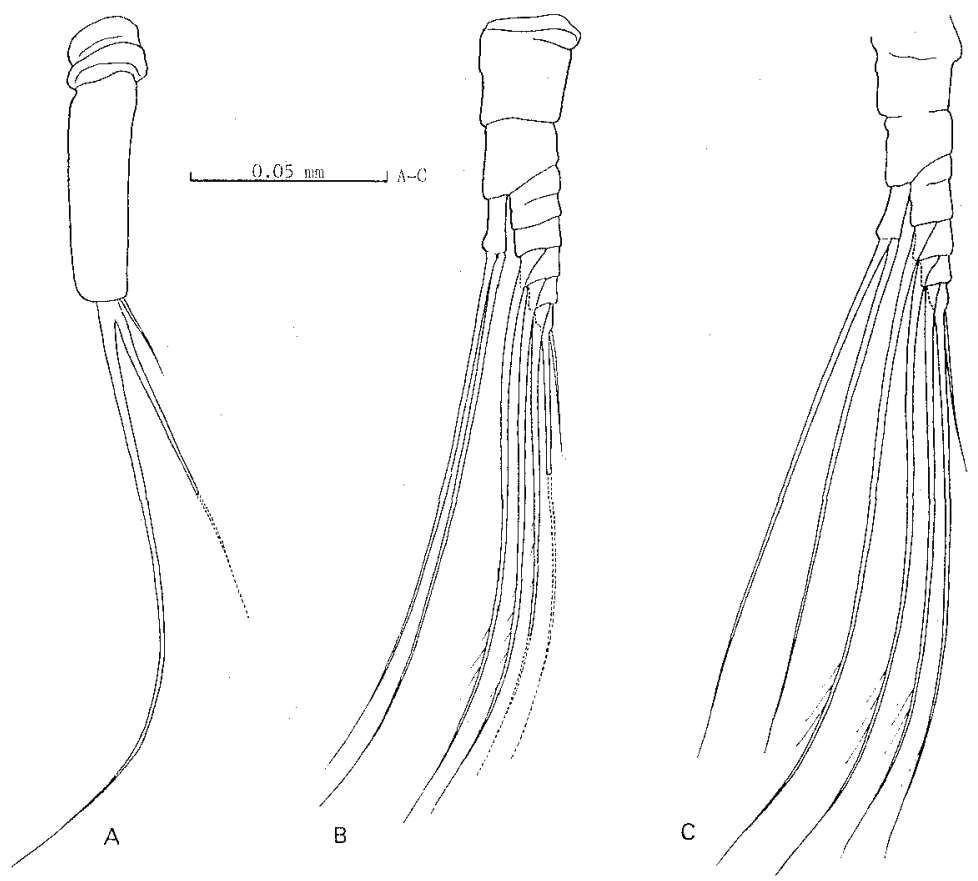

Fig. 4. Nauplius y, type VII. A. First antenna; B. Second antenna; C. Mandible.

a n te n n a (Fig. 4-B). Synpodite with very short precoxa; coxa and basis bare, with no endite. Endopodite represented by a cylindrical segment which does not extend beyond second exopodite segment and is thickened apically, armed with two long apical setae. Exopodite five-segmented, tapering distally; first segment consisting of two incomplete annuli which are demarcated from each other by a partial suture, with no seta; second, third, and fourth segments armed with a long seta on each inner apical edge; fifth segment armed with two apical setae, of which the outer is small. Mandible (Fig. 4-C). Precoxa not clearly separated from coxa. Coxa and basis bare, with no endite. Endopodite as in the first antenna. Exopodite four-segmented, tapering distally; first segment consisting of two incomplete annuli which are demarcated from each other by a partial suture, armed with a long seta on its inner apical edge; second and third segments each armed with an apical seta as in the preceding segment; fourth segment armed with two apical setae as in the fifth segment of the second antenna.

Remarks. This type VII larva is similar to the larva of Hansenocaris pacifica in the general shape of body and in the peculiar features of the second antenna and mandible which do not carry any endite, but is easily discernible from the latter in the sculpture of the cephalic shield. The sculpture of the cephalic shield of the nauplius of $H$. pacifica is represented by polygonal plates even at later stages (Itô, in preparation) and not represented by such a venation-like pattern dominated by 
longitudinal ridges.

The type VII larva does not differentiate a carapace-like structure on its hind body. This characteristic would be useful to distinguish the nauplius larvae of the type VII and $H$. pacifica from the larvae of the other types so far known in the world.

\section{Concluding Remarks}

In a separate paper which dealt with three species of Hansenocaris cyprids (Itô, 1985), I reported two interesting organs, a bifurcate paraocular process and a postocular filamentary tuft. There is no doubt that the bifurcate paraocular process is homologous with a frontal filament of cirriped nauplii and cyprids, though the latter is not bifurcate; moreover, it is highly probable that a bifurcate process of some adult ascothoracids (="second antenna" or "antenna-vestigial eyestalk complex" in the sense of Grygier, 1983a, 1985; "appendice dont la fonction est incertaine" in the sense of Okada, 1938), a process associated with a compound eye found in an ascothoracid cyprid (Grygier, 1983a), and a frontal filament of ascothoracid nauplii (see Okada, 1925) are all homologues of the paraocular process of Hansenocaris cyprids as well as the frontal filament of cirripeds. Furthermore, I am paying attention to some problematic organs which are found even in non-maxillopodan crustaceans such as Speleonectes (Remipedia) (see Itô, 1985, p. 121) and Canadaspis (Phyllocarida): Canadaspis perfecta, which is known from fossils of the Middle Cambrian of Canada, bears a simple, non-articulate process inside each of the paired eyes, and it is called "first antenna" (Briggs, 1978). On the other hand, the identity of the postocular filamentary tuft is still enigmatic, though it might be comparable to a brush-shaped organ known in some ostracods. With regards to these facts and problems, I believe the importance of the knowledge about the development and microanatomy (see Elofsson, 1971) of Hansenocaris nauplii and cyprids must rapidly increase in the near future.

Our knowledge on the geographic distribution of facetotectan larvae in the Pacific is still very poor. However, it is likely that the pelagic larvae recorded by Mileikovskii (1970) as Proteolepas from the North Pacific off the Kuril Islands are facetotectan nauplius larvae because the genus Proteolepas was once used to represent a nauplius y by Steuer (1905) (see Itô, 1985). Although I already reported three species of cypris y (Itô, 1985; see also Itô \& Ohtsuka, 1984, Itô, 1984a) and have described three types of nauplius $y$ in this paper, there is no doubt that more species are distributed in the Pacific and its marginal seas. The larvae reported by me were all collected in Tanabe Bay under a strong influence of the warm Kuroshio, but Mileikovskii's record shows us a possibility that facetotectan larvae are distributed also in the Pacific coastal waters of northern Japan, where the cold Oyashio flowing along the Kuril Islands dominates. I hope this short paper encourages planktologists in Japan who are likely to discover these larvae in their samples. 


\section{References}

Bresciani, J. 1965. Nauplius " $y$ " Hansen. Its distribution and relationship with a new cypris larva. Vidensk. Medd. fra. Dansk Naturh. Foren., 128: 245-258.

Briggs, D.E.G. 1978. The morphology, mode of life, and affinities of Canadaspis perfecta (Crustacea: Phyllocarida), Middle Cambrian, Burgess shale, British Columbia. Phil. Trans. R. Soc. Lond., B, 281 : 439-487.

Elofsson, R. 1971. Some observation on the internal morphology of Hansen's nauplius y (Crustacea). Sarsia, 46:23-40.

Grygier, M.J. 1983a. Ascothoracida and the unity of Maxillopoda. In: F.R. Schram, ed., Crustacean Phylogeny. pp. 73-104. Balkema Publishers, Rotterdam.

- 1983b. A novel, planktonic ascothoracid larva from St. Croix (Crustacea). J. plankt. Res., 5: 197-202.

1985. Comparative morphology and ontogeny of the Ascothoracida, a step toward a phylogeny of the Maxillopoda. Diss. Abst. Int, 45(8) : i-xviii, 1-417.

Hansen, H.J. 1899. Die Gladoceren und Cirripedien der Plankton-Expedition. Ergebnisse der Plankton-Expedition der Humboldt-Stiftung, 2 (G.d): 1-58, pls. I-IV.

Itô, T. 1984a. Another cypris y from the North Pacific, with reference to the bending behavior exhibited by a cypris y speicmen of the formerly described type (Crustacea: Maxillopoda). Publ. Seto mar. biol. Lab., 29: 367-374.

- 1984b. Nauplius y and cypris y (problematic crustacean larvae) from Japan. Zool. Sci., $1: 1000$.

-1985. Contributions to the knowledge of cypris y (Crustacea: Maxillopoda), with reference to a new genus and three new species from Japan. Spec. Publ. Mukaishmia mar. biol. Stn. 1985: 113-122.

—, \& S. Ohtsuka. 1984. Cypris y from the North Pacific (Crustacea: Maxillopoda). Publ. Seto mar. biol. Lab., 29: 179-186.

McMurrich, J.P. 1917. Notes on some crustacean forms occurring in the plankton of Passamaquoddy Bay. Trans. R. Soc. Can., Ser. 3, 11, Sect. 4: 47-61.

Mileikovskii, C.A. 1970. The distribution of pelagic larvae of benthic invertebrates in the KurilKamchatka region. Trudy Inst. Okeanol., 86: 117-133. (In Russian).

Okada, Y.K. 1925. Contribution à l'etude des cirripèdes ascothoraciques. I. Note sur le Dendrogaster arborescens Le Roi; Établissement d'un nouveau genre. Bull. Mus. natn. Hist. nat., Paris, 5: $364-371$.

1938. Les cirripèdes ascothoraciques. Trav. St. zool. Wimereux, 13: 489-512, pl. XXIV.

Schram, T. 1970. On the enigmatical larva nauplius y type I Hansen. Sarsia, 45: 53-68.

-_.... 1972. Further records of nauplius y type IV Hansen from Scandinavian waters. Ibid., $50: 1-24$.

Steuer, A. 1905. Úber eine neue Cirripedien larve aus dem Golfe von Triest. Arb. zool. Inst. Univ. Wien, 15: 113-118. 